\title{
AS TRÊS ANOMALIAS ELÍPTICAS DA PORÇÃO SUL DO CRÁTON SÃO FRANCISCO: NOVOS ALVOS PARA A MINERALIZAÇÃO DE GRAFITA?
}

\author{
Érico Natal Pedro Zacchi' ${ }^{1}$, Adalene Moreira Silva² ${ }^{2}$ Catarina L. Benfica Toledo ${ }^{3}$ \\ e Carlos Roberto de Souza Filho ${ }^{1}$ \\ Recebido em 14 agosto, 2006 / Aceito em 27 novembro, 2007 \\ Received on August 14, 2006 / Accepted on November 27, 2007
}

\begin{abstract}
The southernmost part of the São Francisco Craton (SFC), Minas Gerais, Brazil, comprises early Archean up to late Neoproterozoic rocks. Geologic mapping in this area is limited to regional scales due to the lack of exposed bedrock. In this research, three anomalous, elliptical structures, with an extension over 10 $\mathrm{km}$ along main axis, were first revealed and mapped using high-resolution airborne magnetic and gamma-ray spectrometric data. The structure located at the eastern part of the area hosts the largest graphite mine in Brazil. The other two structures were entirely unknown and absent in previous maps. The merge of geophysical data and remote sensing imagery in a geographic information system provided additional support for the mapping. This successful application of airborne geophysical methods proved their usefulness in regional geologic mapping, which is of fundamental importance to the mining industry.
\end{abstract}

Keywords: airborne geophysical data, geological mapping, Geographic Information System (GIS).

RESUMO. A porção sul do Cráton São Francisco (CSF), Minas Gerais, Brasil, inclui rochas que abrangem desde o Arqueano precoce até o Neoproterozóico tardio. 0 mapeamento geológico e a interpretação estrutural nessa área estão restritos a informações regionais em função dos poucos afloramentos e impossibilidade de correlações laterais. Neste artigo é apresentado o mapa geológico de três anomalias elípticas na porção meridional do CSF, com base no processamento e interpretação de dados aerogeofísicos (magnéticos e raios gama). A anomalia localizada na porção leste da área hospeda uma das maiores minas de grafite no Brasil. As outras duas anomalias, reveladas a partir desse levantamento aerogeofísico, eram até então desconhecidas. A alta resolução dos dados magnéticos e gamaespectrométricos aerotransportados permitiram a definição das estruturas geológicas, a delimitação de unidades litológicas, bem como a possível ocorrência de anomalias adicionais à noroeste da área. A fusão dos dados geofísicos com imagens de sensoriamento remoto num sistema de informações geográficas forneceu subsídios complementares para o mapeamento geológico da área. Este novo exemplo de aplicação bem sucedida de métodos aerogeofísicos demonstra sua utilidade em mapeamentos regionais, os quais são fundamentais para a indústria mineral.

Palavras-chave: geofísica aérea, mapeamento geológico, Sistema de Informações Geográficas.

\footnotetext{
1 Instituto de Geociências, Universidade Estadual de Campinas, Caixa Postal 6152, Campinas, São Paulo, Brasil. Tel.: (19) 3788-4599; Fax: (19) 3289-6215 -E-mails: erico.zacchi@ige.unicamp.br; beto@ige.unicamp.br

2 Instituto de Geociências, Universidade de Brasília, Asa Norte, Brasília, DF, Brasil. Tel./Fax: (61) 3340-4759 - E-mail: adalene@unb.br

${ }^{3}$ Faculdade UnB Planaltina, Universidade de Brasília, Área Universitária n. 1, Vila Nossa Senhora de Fátima, 73300-000 Planaltina, DF, Brasil - E-mail: cattoledo@terra.com.br
} 


\section{INTRODUÇÃO}

A porção sul do Cráton São Francisco é marcada pelo escasso conhecimento geológico devido à cobertura de solos e vegetação, o que dificulta os trabalhos na região. Os custos elevados necessários para a realização de mapeamentos por métodos tradicionais têm elevado a demanda por dados e métodos indiretos. Neste contexto, os levantamentos aerogeofísicos, principalmente gamaespectrométricos e magnéticos, são umas das principais fontes de dados indiretos para interpretação de feições geológicas, particularmente importantes nas etapas exploratórias que antecedem aos trabalhos de campo (Isles et al., 1989; Jaques et al., 1997; Wilford et al., 1997; Silva et al., 2003; Silva, 2003; Teixeira, 2003).

0 Projeto Pitangui-São João Del Rey-Ipatinga foi um projeto de cooperação que envolveu o governo, empresas e universidades, e representa um dos levantamentos aerogeofísicos mais abrangentes já realizados no Brasil quanto à aquisição de dados. Estudos desenvolvidos na região por Silva et al. (2003) mostram que dados desse levantamento aerogeofísico permitem a compartimentalização da geologia regional em blocos distintos, com clara correspondência a sítios datados com idades desde 0 Arqueano ao Neoproterozóico.

Na região de Itapecerica, porção sul do Cráton São Francisco, os dados gamaespectrométricos destacam três estruturas elípticas ainda não individualizadas nos mapeamentos geológicos tradicionais. Na porção interna de uma das estruturas está instalada uma das maiores minas de grafite do Brasil. Nesse contexto, esse estudo visa o mapeamento e entendimento dessas estruturas geológicas, o que pode abrir novas perspectivas para a exploração de grafita na região.

\section{CONTEXTO GEOLÓGICO}

A região da área de estudo está compreendida no Cráton São Francisco Meridional, particularmente no domínio do Complexo Metamórfico Campo Belo. A porção Meridional do Cráton São Francisco (Fig. 1) é composta por terrenos granito-gnáissicos arqueanos, sucessões do tipo greenstone belt arqueanas, rochas metassedimentares paleoproterozóicas e coberturas sedimentares plataformais neoproterozóicas.

A maior parte da porção meridional do Cráton São Francisco é constituída por gnaisses e migmatitos de composição TTG, cujos protólitos se formaram entre 2,9 e 3,2 Ga, intrudidos por granitóides cálcio-alcalinos com idades em torno de 2,78 Ga, e granitóides anorogênicos formados entre 2,7 e 2,6 Ga, além de intrusões máficas e máfico-ultramáficas (Noce et al., 1998; Teixeira et al., 2000). Esses terrenos arqueanos foram divididos em vários complexos metamórficos, distribuídos no cráton meridional.

0 Complexo Metamórfico Campo Belo corresponde à crosta siálica que aflora a oeste do Quadrilátero Ferrífero e do Complexo Metamórfico Bonfim, englobando os antigos complexos Divinópolis e Barbacena (Teixeira et al., 1996; Fernandes, 2001). É constituído por rochas gnáissicas, anfibolíticas e metaultramáficas, intrudidas por gabronoritos, granitóides e gabros. Localmente são encontrados relictos supracrustais (Teixeira et al., 2000), que podem corresponder às sequêencias supracrustais arqueanas e/ou proterozóicas do Quadrilátero Ferrífero.

As rochas gnáissicas têm predominância no complexo e variam de tonalitos a granitos. Os terrenos gnáissicos são divididos em função de sua composição e coloração. Foram discriminados, entre outros, os gnaisses Candeias, Itapecerica e Cláudio. Ocorrências de anfibolito são comumente encontradas na forma de diques deformados, boudins e enclaves encaixados nos gnaisses, paralelos ao bandamento. Rochas metaultramáficas acamadadas (seqüência acamadada Ribeirão dos Motas) são amplamente distribuídas, assim como granadasilimanita-quartzitos. Todo esse conjunto encontra-se cortado por diques gabronoríticos. Uma unidade granítica ocorre na forma de diques de variadas dimensões, ou como grandes corpos intrusivos (Fernandes \& Carneiro, 2000). Com relação ao metamorfismo, a maioria das rochas do Complexo Campo Belo foi gerada ou submetida a condições metamórficas de fácies granulito, com exceção dos gabronoritos, gabros e granitos, que apresentam suas texturas ígneas originais preservadas e paragêneses secundárias de fácies xisto verde (Fernandes \& Carneiro, 2000).

\section{MATERIAIS E MÉTODOS}

Neste trabalho foram utilizados dados aerogeofísicos do Projeto Pitangui-São João Del Rey-Ipatinga (Programa de Levantamento Aerogeofísico do Governo de Minas Gerais) visando auxiliar a caracterização das anomalias elípticas da região sob estudo. A área do levantamento aerogeofísico encontra-se demarcada na Figura 1 (polígono). 0 levantamento aerogeofísico foi efetuado pela empresa Lasa, a encargo da SEME (Secretaria de Estado de Minas e Energia do Estado de Minas Gerais), e seus resultados foram disponibilizados em um relatório final (Lasa, 2001). Os métodos empregados neste levantamento foram 0 magnetométrico e o gamaespectrométrico, com sobrevôo a $100 \mathrm{~m}$ de altitude segundo linhas espaçadas de $250 \mathrm{~m}$, e linhas de controle a cada $2.500 \mathrm{~m}$. A área coberta foi de $36.385 \mathrm{~km}^{2}$, equivalentes a 160.271 km lineares de vôo, com linhas de controle perpendi- 


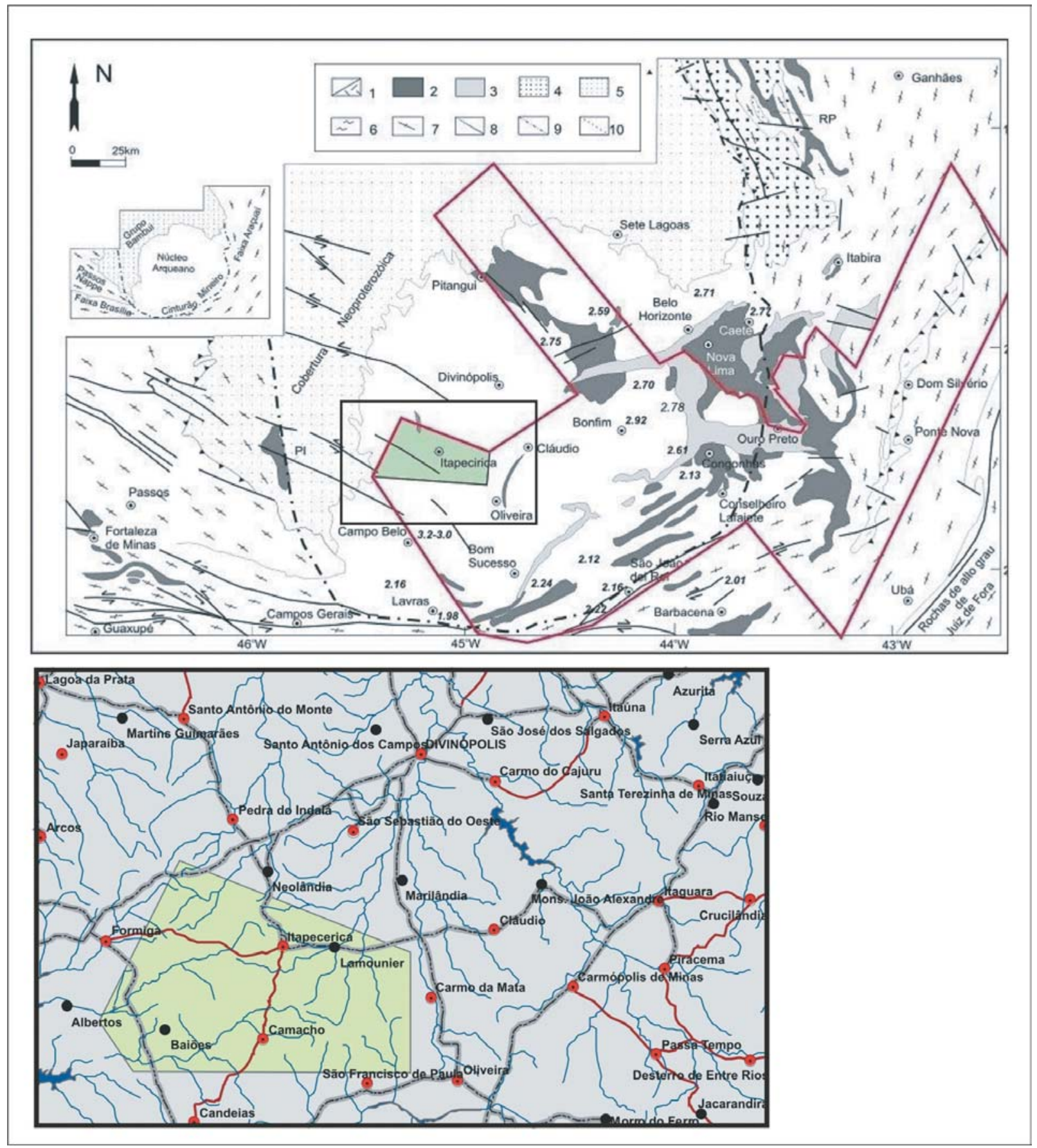

Figura 1 - Mapa Geológico esquemático da Porção Sul do Cráton São Francisco. Notar a delimitação da área em estudo, bem como a área do levantamento aerogeofísico demarcada pelo polígono maior (Modificado de Teixeira et al., 2000). 1 - rochas granitóides-gnaisses-migmatitos e granulitos, parcialmente retrabalhados no Paleoproterozóico (Arqueano); 2 - Greenstone Belts; 3 - Supergrupo Minas (Paleoproterozóico); 4 - Supergrupo Espinhaço (Paleo a Mesoproterozóico); 5 - Grupo Bambuí (Neoproterozóico); 6 - Zona de Cisalhamento/Faixas cisalhadas; 7 - Faixas marginais (Araçuaí, Sul da Faixa Brasília e Nappe de Passos), 8 - Falhas Maiores; 9 - Limite do Cráton; 10 - Foliação Gnáissica. Siglas: PI, RP, FM, CO = Greenstone belts Piumhi, Rio Paraúna, Fortaleza de Minas e Congonhas; DS - Grupo Dom Silvério (Neoproterozóico). 
culares às direções de linha de vôo de N30W e N30E.

A partir dos dados do campo magnético anômalo derivou-se 0 da amplitude do sinal analítico (ASA), que consiste na raiz quadrada da soma dos valores quadráticos das derivadas em $\mathrm{x}$, y e $\mathrm{z}$. A ASA representa a medida da quantidade de magnetização com pouca dependência dos parâmetros da direção de magnetização dos corpos e do campo terrestre (Gunn, 1997). Das três derivadas, a vertical (Dz) representa campos magnéticos nos quais os efeitos regionais e a interferência entre anomalias adjacentes são eliminados (Gunn et al., 1997). As duas derivadas horizontais (Dx e Dy) realçam altas freqüências, podendo proporcionar respostas ambíguas para corpos magnéticos estreitos (Milligan \& Gunn, 1997). A partir da combinação das duas últimas foi derivado o gradiente horizontal total (GHT), que proporciona a possibilidade de verificação de grandes variações laterais. As etapas de processamento dos dados magnetométricos estão ilustradas na Figura 2. Optou-se por gerar mapas em pseudocor; os baixos e altos magnéticos foram representados em azul e vermelho, respectivamente, realçando as estruturas e os domínios litológicos da área de estudo.

A primeira derivada vertical do campo magnético anômalo foi utilizada na delineação de feições estruturais (como contatos, descontinuidades ou lineamentos), os quais são de difícil realce em mapas de campo magnético anômalo.

Na Figura 3 estão discriminadas as etapas utilizadas no processamento dos dados gamaespectrométricos. Foram gerados mapas gamaespectrométricos correspondentes aos canais de $\mathrm{K}$, Th, $\mathrm{U}$ e de contagem total. Da combinação dos três canais (K, Th e U) foram então obtidas as composições ternárias RGB e CMY. Também foi obtido um modelo digital de terreno (MDT) utilizado como uma quarta componente (canal de intensidade) nas combinações ternárias.

A interpretação das imagens foi efetuada no ambiente de um Sistema de Informações Geográficas (SIG), utilizando-se a extensão habitat digitizer (ESRI). Esta extensão permite classificar hierarquicamente polígonos delineados pela interpretação visual. Estas classificações podem ser criadas e modificadas facilmente, 0 que representa grande vantagem no trabalho de mapeamento geológico.

A interpretação qualitativa dos dados gamaespectrométricos foi efetuada, principalmente, através das composições ternárias RGB (Red, Green e Blue) e CMY (Cyan, Magenta e Yellow), geradas a partir dos canais de $\mathrm{K}$, Th e $\mathrm{U}$. Tal análise possibilitou a definição de domínios gamaespectrométricos com assinaturas semelhantes, que constituem um importante guia para a etapa de campo, sob a forma de um mapa litogeofísico.
Os dados gamaespectrométricos também foram utilizados para correlacionar a topografia com a dispersão de radioelementos através do intemperismo e da pedogênese, e diferenciar suas possíveis fontes entre primárias e secundárias. Isso foi possível pela análise integrada dos dados geofísicos associados aos dados altimétricos do SRTM (Shuttle Radar Topography Mission). Esses dados foram gerados por meio da tecnologia de interferometria SAR (InSAR) entre os dias 11 e 22/02/2000, a bordo do ônibus espacial Endeavour, e cobrem cerca de 80\% da superfície da Terra. Atualmente, constitui o mais completo banco de dados topográficos de alta resolução disponível em escala global. Estes dados, utilizados na forma de modelo digital de elevação (MDE), apresentam resolução espacial original de $1 \operatorname{arc} \sec (\sim 30 \mathrm{~m})$. Os dados disponíveis para a América do Sul tiveram sua resolução espacial reduzida para 3 arc sec $(\sim 90 \mathrm{~m})$. O SRTM operou simultaneamente com duas antenas, respectivamente nas bandas C e X. Para a composição do modelo digital integrado de elevação da área de estudo serão utilizados os dados com resolução espacial de $\sim 90 \mathrm{~m}$ da banda $\mathrm{C}$.

Quando associados aos dados gamaespectrométricos, especificamente a composição ternária RGB, os dados do SRTM evidenciam a relação entre a assinatura geofísica e a topografia, com destaque para as estruturas elípticas da região de Itapecerica (Fig. 4).

\section{RESULTADOS E DISCUSSÃO}

$\mathrm{Na}$ interpretação dos dados gamaespectrométricos 0 esquema de classificação adotado levou em consideração a variação na concentração dos teores de potássio, urânio e tório, sendo cada um dos canais dividido em três categorias (alto, médio e baixo), gerando 27 diferentes possibilidades de classificação. Com base nesta metodologia foram definidas 18 unidades gamaespectrométricas para a região em estudo, que estão representadas no mapa litogeofísico elaborado na escala 1: 50.000 e apresentado na escala 1: 250.000 (Fig. 5).

Em um terreno altamente intemperizado, como 0 deste estudo, torna-se fundamental a melhor compreensão e caracterização da relação entre o relevo e a dispersão dos radioelementos e sua influência no aerolevantamento. Desta forma, os dados gamaespectrométricos foram integrados a dados do sensor SRTM para a geração de modelos digitais de elevação. Utilizouse a composição ternária CMY, o canal individual de potássio e os mapas de razão $\mathrm{U} / \mathrm{K}$ e U/Th.

Os mapas de razão apresentam, por exemplo, áreas enriquecidas em urânio e empobrecidas em potássio, na coloração ver- 


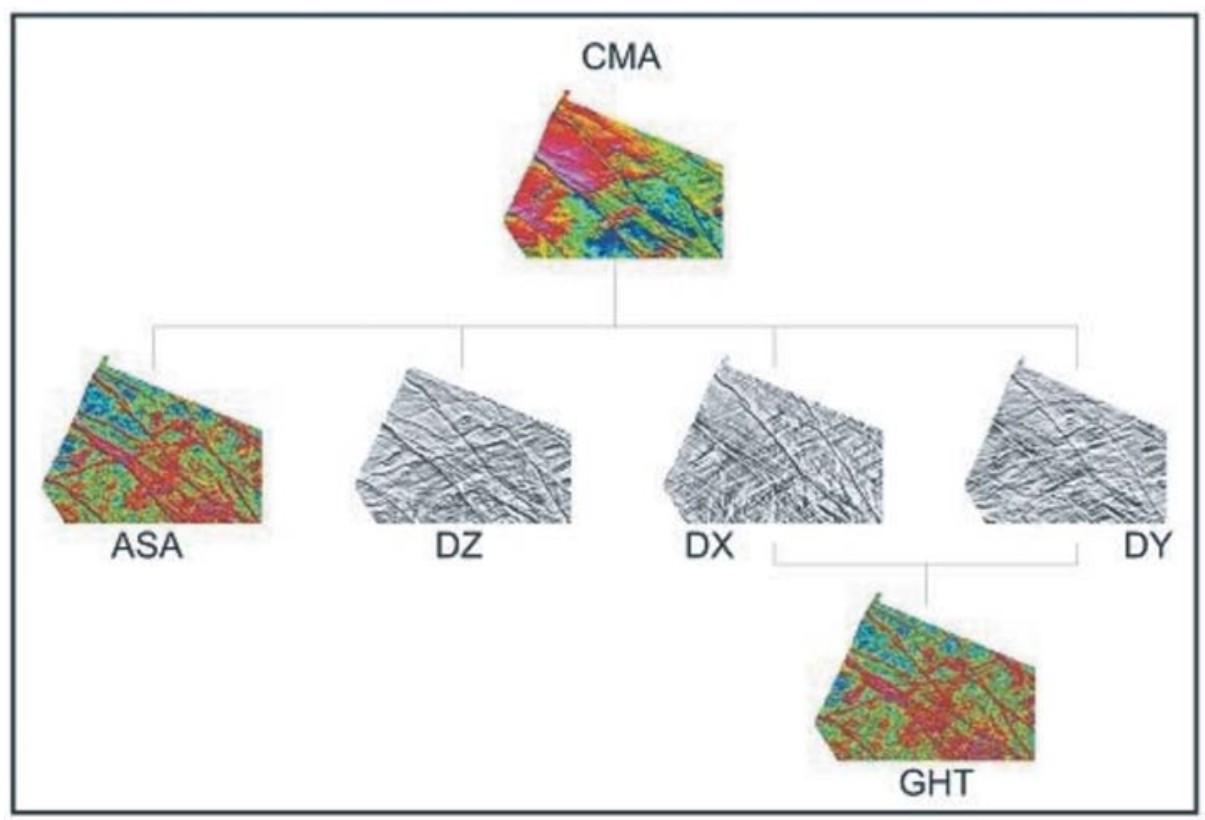

Figura 2 - Etapas do processamento dos dados aeromagnéticos. CMA - Campo Magnético Anômalo (unidade em nT = nanoTesla); ASA - Amplitude do Sinal Analítico (unidade em $\mathrm{nT} / \mathrm{m}$ ); DZ - Primeira Derivada Vertical em Z (unidade em $\mathrm{nT} / \mathrm{m}$ ); DX - Primeira Derivada Horizontal em X (unidade em $\mathrm{nT} / \mathrm{m}$ ); DY - Primeira Derivada Horizontal em Y (unidade em $\mathrm{nT} / \mathrm{m}$ ); GHT - Gradiente Horizontal Total (unidade em nT/m).

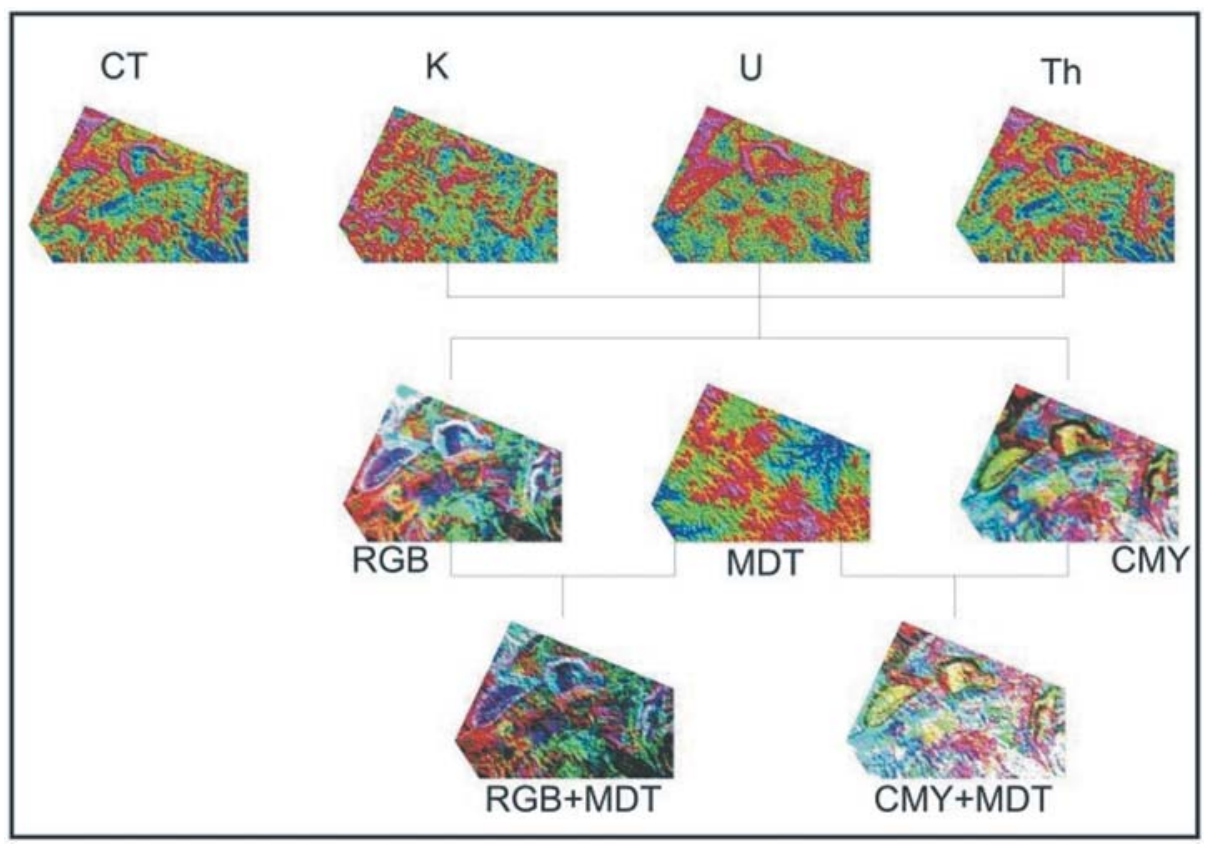

Figura 3 - Etapas do processamento dos dados aerogamaespectrométricos. CT - Contagem Total (concentração em $\mu \mathrm{R} / \mathrm{h}$, onde $\mu=$ coeficiente de atenuação atmosférica; $\mathrm{R}=$ Roentgen; $\mathrm{h}=$ hora); $\mathrm{K}$ - Canal de potássio (concentração em \%); $\mathrm{U}-\mathrm{Ca}$ nal de urânio (concentração em ppm); Th - Canal de tório (concentração em ppm); RGB - Composição ternária dos canais de radioelementos (Red = K; Green = Th; Blue = U); MDT - Modelo Digital de Terreno (unidade em metros); CMY - Composição ternária a partir dos canais de radioelementos $($ Cyan = K; Magenta = Th; Yellow = U). 


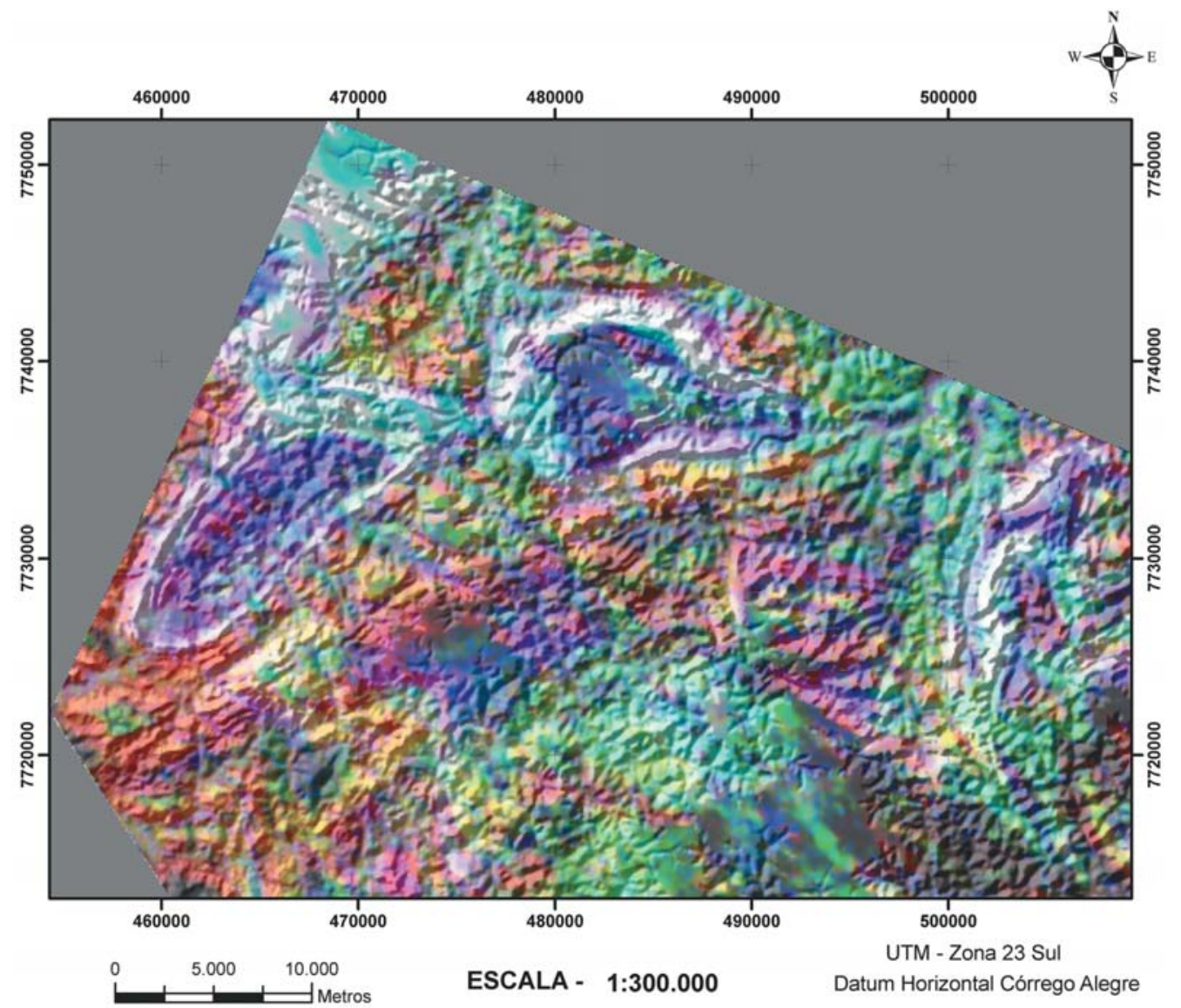

Figura 4 - Integração dos dados gamaespectrométricos com dados do sensor SRTM, ressaltando a relação entre a assinatura geofísica e o relevo.

melha, enquanto as porções representadas em azul correspondem à situação inversa (baixo U e alto K).

No caso do modelo produzido com as razões $\mathrm{U} / \mathrm{K}$ e Th/K, é possível observar a alta concentração de U e Th no topo de platôs. Esses compartimentos topográficos permitem boa infiltração das águas, com a lixiviação dos produtos dissolvidos, principalmente 0 potássio e 0 urânio. Os minerais secundários formados tendem a ter uma composição simples, como óxidos de ferro, minerais resistatos e caulinita, onde a sílica não foi totalmente lixiviada, concentrando urânio e tório. No modelo em que foi utilizado apenas 0 canal de potássio é possível notar que este elemento se concentra em rochas mais resistentes ao intemperismo, como as que ressaltam as anomalias elípticas no relevo, e ao longo dos perfis dos platôs, logo abaixo do nível enriquecido em urânio e tório. Isto sugere que um pequeno manto de alteração se sobrepõe à resposta das fontes primárias dos raios gama durante 0 aerolevantamento, prejudicando a interpretação. Também são destacadas concentrações de potássio ao longo de drenagens próximas às possíveis áreas-fonte, o que sugere erosão, transporte e deposição dos sedimentos relativamente rápidos, com pouco tempo para que o intemperismo modificasse a composição radiométrica da fonte original. Através da composição ternária CMY é possível observar que no alto de platôs há baixa concentração de radioelementos, indicando solos com alto teor de sílica, possivelmente originada a partir de porções de uma rocha composicionalmente rica em potássio, porém pobre em outros radioelementos (Fig. 6).

Já as feições estruturais interpretadas através dos dados magnetométricos indicam que a maior parte dos lineamentos apresenta coerência com um possível enxame de diques, ressaltado pelo mapa da amplitude do sinal analítico.

Apoiada nesses resultados preliminares foi realizada a etapa de campo na região, com o intuito de associar diferentes variações na concentração de radioelementos com os diferentes litotipos mapeados.

Dickson \& Scott (1997) ressaltam que dentro de um dado 


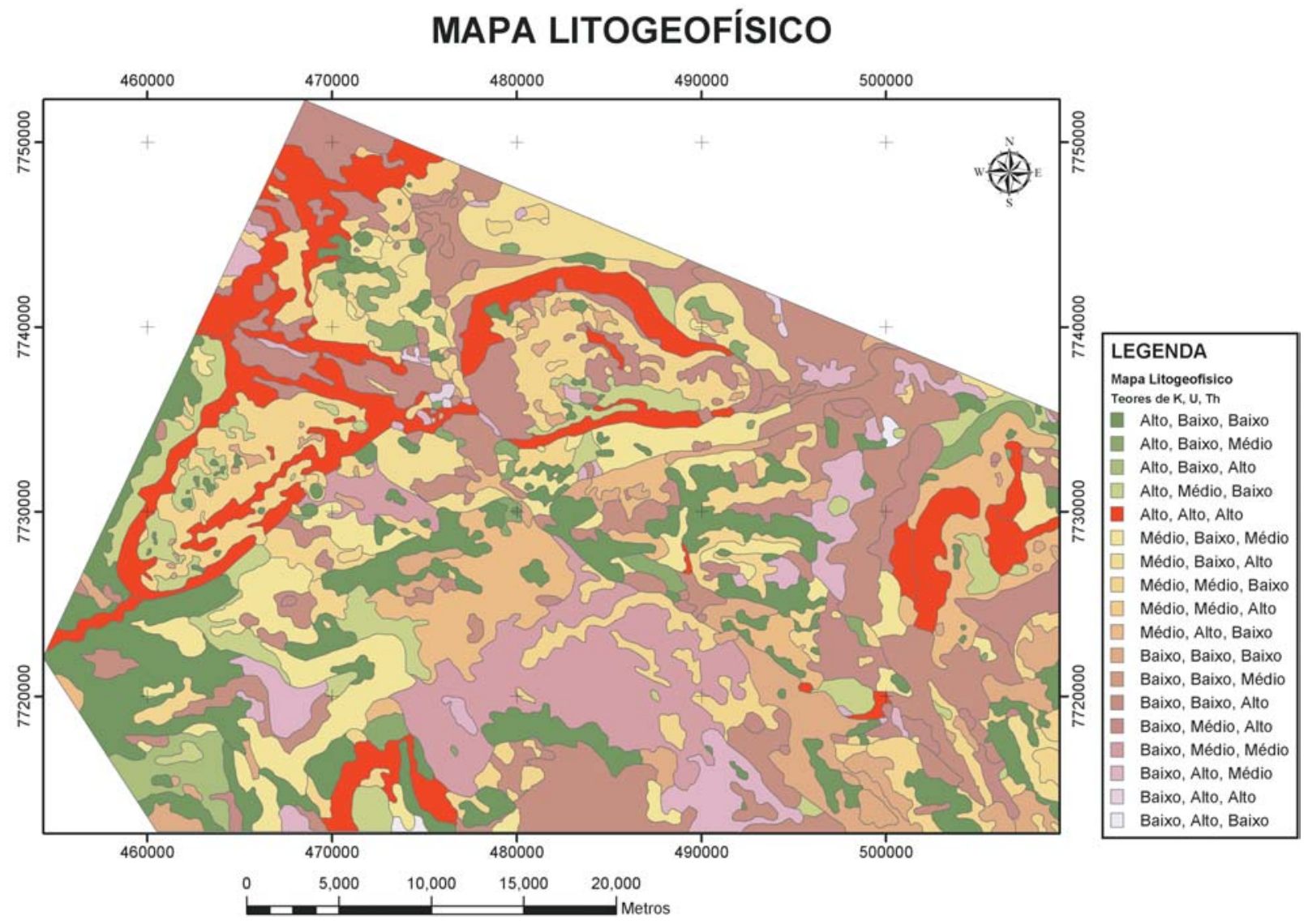

Figura 5 - Mapa litogeofísico da região de Itapecerica (MG), gerado a partir da interpretação em ambiente SIG das composições ternárias RBG e CMY.

tipo de rocha pode existir uma ampla variação das concentrações de radioelementos, o que inviabiliza uma classificação petrográfica generalizada. Porém, diferentes tipos de rocha podem ser identificados com base em suas concentrações relativas. A partir da análise integrada dos dados de campo e do mapa litogeofísico previamente elaborado, procurou-se separar as unidades geológicas com base em suas características geofísicas. Ao final o mapa litogeofísico foi simplificado e restrito a seis unidades litológicas amostradas (Fig. 7), resultando no mapa geológico preliminar proposto para a área, apresentado na escala 1: 250.000 (Fig. 8).

\section{CONCLUSÕES}

As concentrações relativas de radioelementos variam conforme previsto na área de estudo, ou seja, maiores teores de radioelementos correspondem a rochas com maiores concentrações de sílica, ao passo que as ocorrências de corpos máficos estão associadas a sítios de baixa concentração.

A sequiência metassedimentar localizada no interior da ano- malia elíptica de Itapecerica apresenta assinatura caracterizada por altas concentrações de urânio, com pontos localizados de alto teor de potássio. 0 teor médio de urânio em rochas sedimentares é estimado em aproximadamente 3 ppm, porém alguns sedimentos como folhelhos, carvões e fosfatos apresentam teores bem acima desse patamar. As elevadas concentrações de potássio podem ser relacionadas a intrusões de álcali-granitos registradas na base da seqüência.

As rochas de característica granítica a granodiorítica correspondem aos halos externos das estruturas elípticas e são caracterizadas no mapeamento litogeofísico pela alta concentração de radioelementos. Os gnaisses foram divididos em três unidades. A primeira é representada pelo gnaisse granítico mapeado próximo à Capivara - a sua assinatura gamaespectrométrica varia entre teores intermediários de $\mathrm{K}$ e Th à elevados de $\mathrm{K}$. A segunda unidade é representada pelo gnaisse localizado próximo de Lamounier, caracterizado por teores de potássio mais elevados comparativamente aos demais gnaisses mapeados. A terceira unidade gnáissica é constituída por um gnaisse granu- 

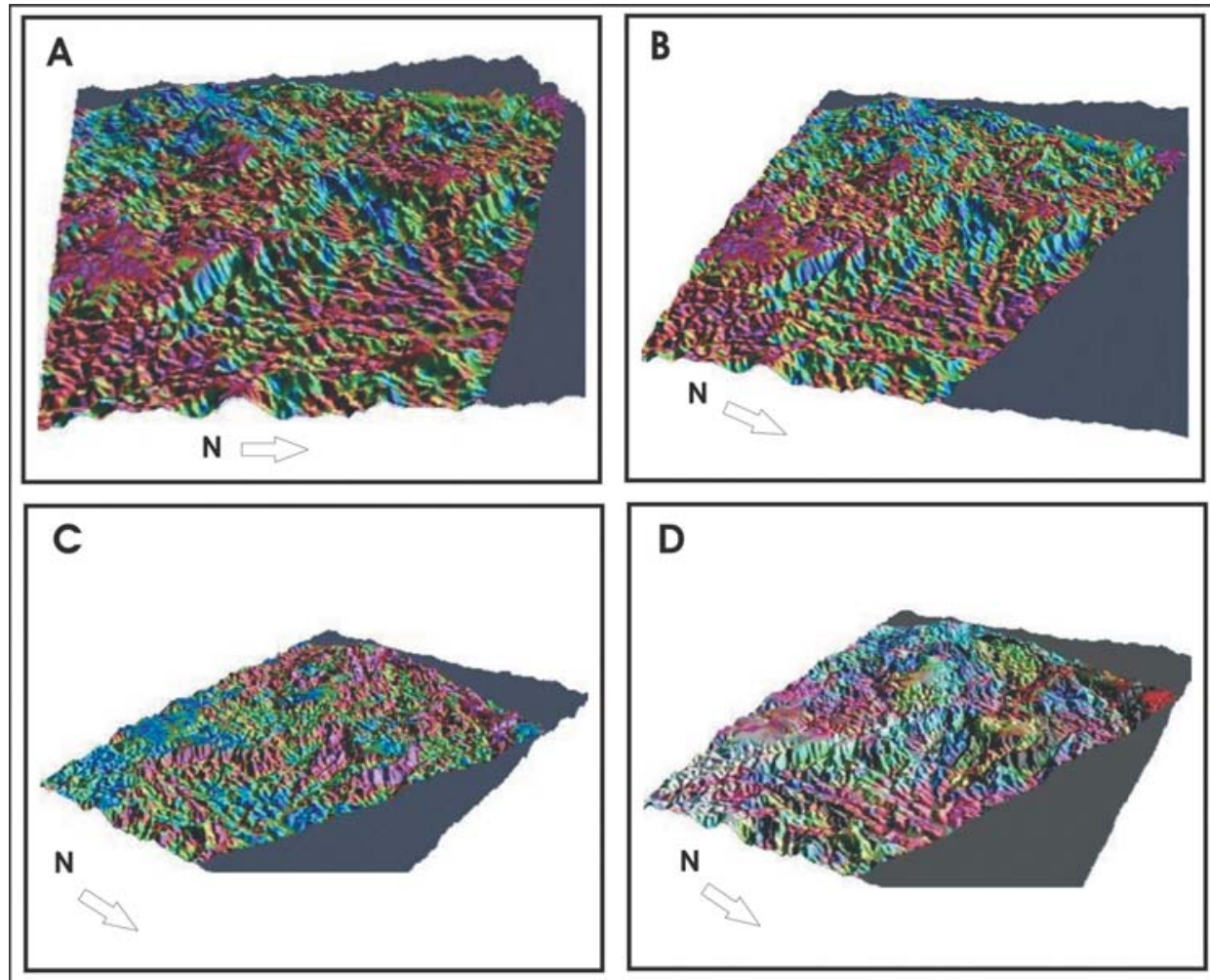

Figura 6 - Modelos gerados através da integração de dados gamaespectrométricos e do sensor SRTM: A) razão dos canais U/K; B) razão dos canais Th/K; C) Canal individual do K; D) Composição ternária CMY.
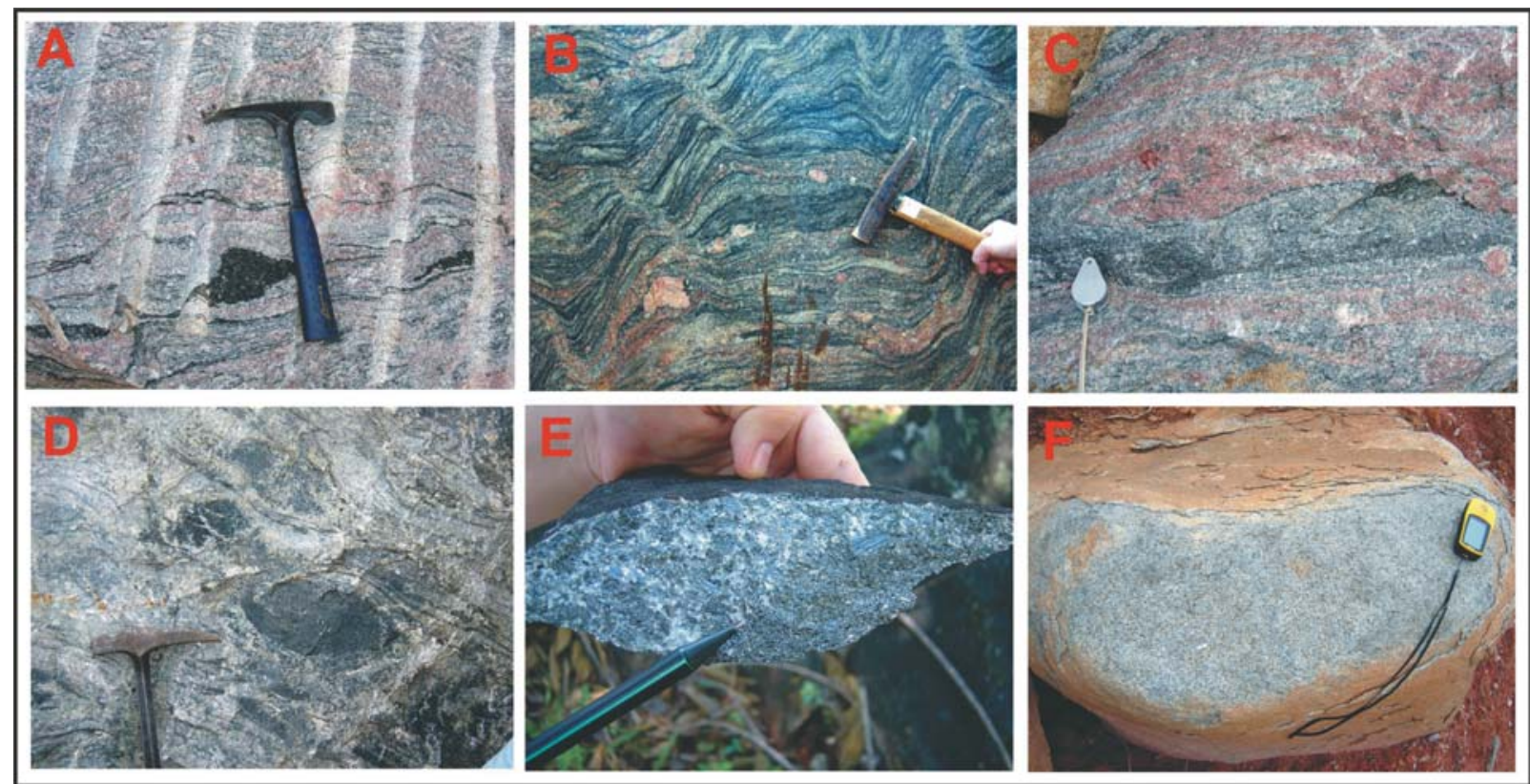

Figura 7 - Litotipos amostrados: A) Unidade Granítica; B) Biotita Gnaisse Granodiorítico; C) Granada-Biotita Gnaisse Granítico; D) Epidoto-Biotita Gnaisse Tonalítico; E) Unidade Anfibolítica; F) Metagabro (mapeado com auxílio da magnetometria). 


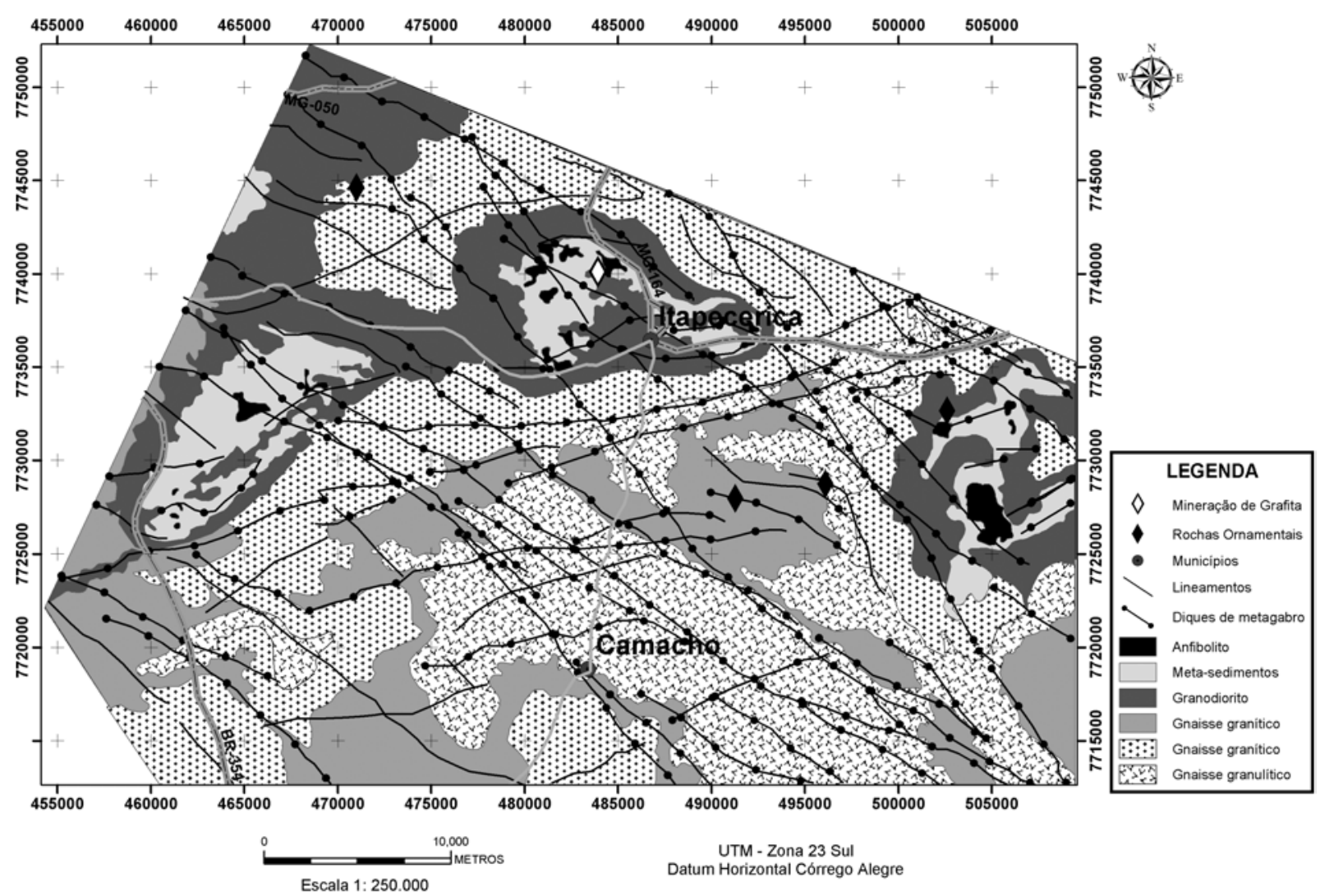

Figura 8 - Mapa Geológico da região de Itapecerica, obtido a partir da integração de dados aerogeofísicos e dados geológicos.

lítico, cuja assinatura gamaespectrométrica aponta para elevada concentração de urânio, sendo a sua maior ocorrência na área próxima à Camacho.

Os corpos de anfibolitos encontrados no limite leste da área, próximo à Serra de Cláudio, foram agrupados em uma unidade cuja assinatura característica corresponde à baixa concentração de radioelementos. Sua ocorrência é restrita a pequenos corpos associados às unidades anteriormente descritas, geralmente na forma de xenólitos. A unidade correspondente à unidade máfica fissural da região de Itapecerica não têm expressão na gamaespectometria, mas teve boa resposta na magnetometria, o que é evidenciado pelo mapeamento de dique de metagabro.

As estruturas elípticas parecem corresponder a uma macrofigura de interferência refletindo a superposição de dobras (Ramsay, 1967). Esse padrão de interferência apresenta extensão regional e está bem caracterizado na área do depósito de grafita, onde estruturas lineares, principalmente eixos de dobras, variam ligeiramente em torno da direção $\mathrm{N} 40^{\circ} \mathrm{E}$. Nessa área observa-se que houve grandes empurrões de $\mathrm{N}$ para $\mathrm{S}$ (estrias), resultado de uma fase de redobramento com eixos secundários na mesma direção da camada (Resende \& Varella, 1997). Dentro da mina do Tejuco Preto, o xisto grafitoso tem atitude geral $\mathrm{N} 40^{\circ} \mathrm{E}$ com mergulhos de $10^{\circ}$ a $20^{\circ} \mathrm{SW}$, enquanto localmente ocorrem dobramentos para $\mathrm{N}$ e para $\mathrm{S}$.

Em virtude da complexidade geológica do terreno e da escala das estruturas observadas, apenas um levantamento estrutural detalhado permitirá a elaboração de um modelo estrutural. Porém, cabe ressaltar que apenas através dos dados gamaespectrométricos foi possível a caracterização deste padrão estrutural elíptico, que além de permitir uma nova contribuição para a compreensão da evolução geológica da região, possibilita ainda uma reinterpretação de dados prévios na área.

\section{AGRADECIMENTOS}

À SEME-CODEMIG pela cessão dos dados aerogeofísicos da área II - Levantamentos Geofísicos de MG, especialmente ao Dr. Marcelo Nassif e à geóloga Andrea Vaz de Mello França. Ao Projeto Fapesp - Projeto "Processamento, Interpretação e Integração de dados aplicados à exploração de metais preciosos em terrenos tropicais", Proc. No 02/090038-6. Ao Conselho 
Nacional de Desenvolvimento Científico e Tecnológico (CNPq) pela bolsa de Iniciação Científica.

\section{REFERÊNCIAS}

DICKSON BL \& SCOTT KM. 1997. Interpretation of aerial gamma-ray surveys - adding the geochemical factors. AGSO Journal of Australian Geology \& Geophysics, 17(2): 187-200.

FERNANDES RA. 2001. Etapas da formação da crosta continental (do Mesoarqueano ao Mesoproterozóico) no Cráton São Francisco Meridional. Tese de Mestrado. UFOP/Instituto de Geociências. 128 p.

FERNANDES RA \& CARNEIRO MA. 2000. O Complexo Metamórfico Campo Belo (Cráton São Francisco Meridional): unidades litodêmicas e evolução tectônica. Revista Brasileira de Geociências, 30(4): 671-678.

GUNN PJ. 1997. Quantitative methods for interpreting aeromagnetic data: a subjective review. AGSO Journal of Australian Geology \& Geophysics, 17(2): 105-113.

GUNN PJ, MAIDMENT D \& MILLIGAN PR. 1997. Interpreting aeromagnetic data in areas of limited outcrop. AGSO Journal of Australian Geology \& Geophysics, 17(2): 175-182.

ISLES DJ, HARMAN PG \& CUNNEM JP. 1989. The Contribution of High Resolution Aeromagnetics to Archean Gold Exploration in the Region. Western Australia. Economic Geology, Monograph, 6: 389-397.

JAQUES AL, WELLMAN P, WHITAKER A \& WYBORN D. 1997. Highresolution Geophysics in Modern Geological Mapping. AGSO Journal of Australian Geology \& Geophysics, 17(2): 159-173.

LASA ENGENHARIA E PROSPECÇÕES S.A. 2001. Relatório final do levantamento e processamento dos dados magnetométricos e gamaespectrométricos. Levantamento Aerogeofísico de Minas Gerais, Área 2. Projeto Pitangui-São João Del Rey-Ipatinga. Volume I, Texto técnico. 67 p.

MILLIGAN PR \& GUNN PJ. 1997. Enhancement and presentation of airborne geophysical data. AGSO Journal of Australian Geology \& Geophysics, 17(2): 63-75.
NOCE CM, MACHADO N \& TEIXEIRA W. 1998. U-Pb Geochronology of gneisses and granitoids in the Quadrilátero Ferrífero (Southern São Francisco Craton): age constraints for Archean and Paleoproterozoic magmatism and metamorphism. Rev. Bras. Geoc., 28: 95-102.

RAMSAY JG. 1967. Folding and Fracturing of Rocks. McGraw-Hill, $568 \mathrm{p}$.

RESENDE EF \& VARELLA JCS. 1997. Principais depósitos minerais do Brasil. Vol. IV - Rochas e Minerais Industriais. Parte C. DNPM. Brasília. $185 \mathrm{p}$.

SILVA AAC. 2003. Processamento, Interpretação e integração de Dados Geológicos e Geofísicos da Província Mineral Tapajós, UnB/Instituto de Geociências, 137 p.

SILVA AM, DE SOUZA FILHO CR, TOLEDO CLB \& DANTAS EL. 2003. Amalgamation of Different Crustal Blocks in the Southernmost Part of the São Francisco Craton constrained by Airborne Geophysical Data, Brazil. Proceedings of the $8^{\text {th }}$ International Congress of the Brazilian Geophysical Society and $5^{\text {th }}$ Latin American Geophysical Conference, 2003, Rio de Janeiro. CD-ROM.

TEIXEIRA AA. 2003. Integração de Dados Multifontes para Exploração de Ouro no Greenstone Belt Rio das Velhas, Quadrilátero Ferrífero, Minas Gerais, UnB/Instituto de Geociências, 157 p.

TEIXEIRA NA, FRANKE ND, BRENNER TL \& MARCHETTO C. 1996. Polymetallic sulfides and manganese deposits of Itumirim-Nazareno greenstone belt. An example of sub-seafloor geothermal system. In: SBG, Congresso Brasileiro de Geologia, 39, Salvador, Anais: 326-328.

TEIXEIRA W, SABATÉ P, BARBOSA J, NOCE CM \& CARNEIRO MA. 2000. Archean and Paleoproterozoic tectonic evolution of the São Francisco Craton, Brazil. In: CORDANI UG, MILANI EJ, THOMAZ FILHO A \& CAMPOS DA. (Ed.). Tectonic Evolution of South America. $31^{\text {st }}$ International Geological Congress, Rio de Janeiro. p. 101-137.

WILFORD JR, BIERWIRTH PN \& CRAIG MA, 1997. Application of Airborne Gamma-ray Spectrometry in Soil/regolith Mapping and Applied Geomorphology. AGSO Journal of Australian Geology \& Geophysics, 17(2): 201-216.

\section{NOTAS SOBRE OS AUTORES}

Érico Natal Pedro Zacchi. Graduando em Geologia pela Universidade Estadual de Campinas, e membro do Grupo de Geotecnologias do IG/UNICAMP.

Adalene Moreira Silva. Engenheira Geóloga (1989) graduada pela Universidade Federal de Ouro Preto, Mestre (1992) e Doutora em Geologia (1999) pela Universidade de Brasília. Profissionalmente foi pesquisadora do Serviço Geológico Americano (1997-1999); Professora visitante da Universidade de Brasília (2000-2002); Pesquisadora (05/2002-04/2003) e Professora do Instituto de Geociências da UNICAMP (04/2003-10/2005). Atualmente é Professora do Instituto de Geociências da Universidade de Brasília; e vem ensinando e pesquisando sobre novas técnicas de processamento, interpretação e integração de dados aplicadas à exploração mineral, hidrogeologia e ambiente

Catarina Labouré Benfica Toledo. Possui graduação em Geologia pela Universidade Federal do Rio de Janeiro (1990), mestrado em Geociências pela Universidade Estadual de Campinas (1997), doutorado em Geociências pela Universidade Estadual de Campinas (2002) e pós-doutorado pela Universidade Estadual Paulista - 
Departamento de Petrologia e Metalogenia (2006). Atualmente é Professora Adjunta da Universidade de Brasília. Tem experiência na área de Geociências, com ênfase em Geologia e tem atuado principalmente nos seguintes temas: rochas máficas e ultramáficas, komatiitos, basalto toleítico, corpos acamadados, metamorfismo e geoquímica.

Carlos Roberto de Souza Filho. Engenheiro Geólogo, graduado pela Universidade Federal de Ouro Preto em 1988, Mestre em Metalogênese pela UNICAMP em 1991, PhD pela Open University (Inglaterra) em 1995, Jovem-Pesquisador da FAPESP-UNICAMP entre 1995-1997, Professor-Doutor da UNICAMP entre $1997-2002$. Desde 2002, é Professor Livre Docente do Departamento de Geologia e Recursos Naturais do Instituto de Geociências da UNICAMP. Atualmente é Coordenador do Programa de Pós-graduação de Geociências e líder do Grupo de Geotecnologias do IG. Pesquisador Nível 1 do CNPq, é o responsável pelos laboratórios de pesquisa em Fs-LA-ICP-MS (IsoGeo), Espectroscopia de Reflectância (LER) e Processamento de Informações Georreferenciadas (LAPIG) do Instituto. É pesquisador da NASA nos programas ASTER e Mars-Earth Analogs, Editor-associado da Revista Computers \& Geosciences, e membro do corpo editorial e consultivo da Mathematical Geology, do International Journal of Remote Sensing, da Meteoritics and Planetary Sciences e da Revista Brasileira de Geociências. Seus trabalhos de pesquisa mais recentes compreendem 0 uso de Geotecnologias (sensoriamento remoto, geofísica, processamento digital de imagens, sistemas de informações georreferenciadas; sistemas especialistas; geoestatística) aplicadas multidisciplinarmente ao estudo de recursos naturais terrestres e em ciências planetárias. 